\title{
The importance of fieldwork over predictive modeling in quantifying predation events of carnivores marked with GPS technology
}

\author{
L. Mark Elbroch, * Blake Lowrey, and Heiko U. Wittmer \\ Panthera, 8 West 40th Street, 18th Floor, New York, NY 10018, USA (LME) \\ Systems Ecology Program, Division of Biological Sciences, University of Montana, 32 Campus Drive, Missoula, MT 59812, \\ USA $(B L)$ \\ School of Biological Sciences, Victoria University of Wellington, P.O. Box 600, Wellington 6140, New Zealand (HUW)
}

*Correspondent: melbroch@panthera.org

\begin{abstract}
Global positioning system (GPS) technology has revolutionized the study of carnivores. Researchers commonly estimate kill rates with GPS data using the following steps. Firstly, researchers mark individual animals and fit them with GPS collars. Next, they visit a subset of "GPS clusters" (aggregated location data) during field surveys and assign spatiotemporal covariates associated with predation and non-predation events. Lastly, they develop predictive models with data collected in the field to estimate the probability that each cluster they did not visit in the field was a predation event. Such predation models help reduce field efforts and save money; however, these models are prone to error when carnivores eat prey of different sizes or exhibit shorter-than-expected handling times. We simulated reduced field efforts to investigate the reliability of predictive modeling in determining diet composition and detecting predation events for 3 puma (Puma concolor) populations with different prey assemblages and potential effects on handling time of carcasses. We visited a total 1,896 clusters in Chilean Patagonia, Colorado, and California, of which 1,752 clusters ( 92\%) were included to build and test predation models. Across all study areas, the total time a puma spent at a cluster was the only reliable predictor of a cluster being a predation event. When we reduced field efforts by selectively removing GPS clusters $<12$ and $<24 \mathrm{~h}$ in length, model performance improved but produced inaccurate results. Predation models underestimated the number of predation events in California and Colorado and significantly over- or underestimated the number of predation events in Patagonia. Selectively reducing field efforts also reduced the diversity and evenness of prey we recorded in puma diets. Randomly reducing field efforts, in contrast, reduced the precision of model estimates. Our results highlight the importance of conducting intensive fieldwork over predation modeling to measure prey selection and kill rates of carnivores.
\end{abstract}

La tecnología de Sistemas de Posicionamiento Global (GPS) han revolucionado el estudio de los carnívoros. Los investigadores comúnmente estiman las tasas de obtención de presas con datos de GPS. Primero, los investigadores marcan animales individuales y luego examinan un subconjunto de "conglomerados" (datos agregados de ubicación) a nivel de campo; luego, asignan covariables espaciotemporales asociadas con eventos de depredación y sitios sin obtención de presas; por último, desarrollan modelos predictivos que estiman la probabilidad de que cada agregado que no visitaron en campo corresponda a un evento de depredación. Los modelos de depredación reducen los esfuerzos de campo y ahorran dinero; sin embargo, dichos modelos son propensos a error cuando los carnívoros consumen presas de diferentes tamaños o exhiben tiempos de procesamiento más cortos de lo esperado. Simulamos esfuerzos de campo reducidos para investigar la confiabilidad del modelaje predictivo para la determinación de la composición de la dieta y los eventos de depredación de tres poblaciones de puma (Puma concolor) en la Patagonia chilena, Colorado y California, con diferentes conjuntos de presas y efectos sobre el tiempo de procesamiento de las carcasas. Revisamos 1,896 conglomerados en el campo, de los cuales se incluyeron 1,752 ( 92\%) para construir y comprobar modelos predictivos de depredación. El tiempo total que

(C) 2017 American Society of Mammalogists, www.mammalogy.org 
un puma pasó en un conglomerado fue el único predictor confiable de que éste fuera un evento de depredación en el área de estudio. Cuando redujimos los esfuerzos de campo removiendo selectivamente conglomerados de GPS con $<12$ horas y 24 horas de duración, el rendimiento del modelo mejoró (determinado con curvas ROC y validación cruzada de $k$-iteraciones) pero produjo resultados inexactos. Estos modelos subestimaron el número de eventos de depredación en California y Colorado, y sobre- y subestimaron significativamente la cantidad de eventos de depredación en la Patagonia. La reducción selectiva de los esfuerzos de campo también redujo la diversidad de presas que registramos en las dietas de puma. En contraposición, con la reducción aleatoria de los esfuerzos de campo, se redujo la precisión de las estimaciones del modelo. Nuestros resultados resaltan la importancia del trabajo de campo intensivo respecto al modelado de conglomerados para medir la selección de presas y las tasas de depredación de carnívoros medianos y grandes.

Key words: diet composition, fieldwork, GPS clusters, kill rates, natural history, predator-prey interactions

Understanding the impact of predators on prey populations remains a central theme of ecological research, even after more than a century of attention (e.g., Holling 1959; Hopcraft et al. 2010). Assessing the impact of predators on prey often relies on estimates of kill rates, the number of prey killed per predator per unit time (Holling 1959), and prey selection, which can subsequently be used to model predator-prey dynamics and provide insight into the conservation and management of both predators and their prey (White and Lubow 2002). Kill rates are also useful when investigating species interactions in complex multispecies communities, including apparent (Holt and Lawton 1994; Wittmer et al. 2013), interference, and exploitation competition (Krofel et al. 2012), as well as the influence of human development on the behaviors of large carnivores (Smith et al. 2015).

Historically, researchers estimated kill rates and prey selection using direct observation of predators, snow tracking of focal animals, intensive radiotracking of animals tagged with VHF transmitters, or some combination of these techniques. Researchers can complement such methods with bioenergetics modeling to predict kill rates for cryptic and wide-ranging carnivores (Ackerman et al. 1984; Głowaciński and Profus 1997). The development of global positioning system (GPS) collars, however, revolutionized the study of carnivores by providing researchers with high-resolution location data and a more efficient means of locating, identifying, and counting prey killed by predators.

In their pioneering work on pumas (Puma concolor), Anderson and Lindzey (2003) first mapped "GPS clusters" ( $\geq$ 2 GPS points within $200 \mathrm{~m}$ of each other recorded between 1600 and $0800 \mathrm{~h}$ during the same night) to identify potential predation sites. They visited a subset of these GPS clusters in the field and classified each site as a predation or non-predation event. Next, they used spatiotemporal descriptive covariates for each cluster and built predictive models to estimate the probability of an unknown cluster being a predation event. Lastly, they fit predation models to large data sets gathered over longer sampling intervals to estimate the probability of every cluster being a predation event, while simultaneously reducing field efforts and increasing cost savings (Merrill et al. 2010; Blecha and Alldredge 2015).

The current steps for detecting predation events based on GPS clusters are essentially unchanged since Anderson and
Lindzey's (2003) original work. Researchers generally 1) deploy GPS collars on animals; 2) identify GPS clusters based upon temporal and spatial characteristics, either visually (e.g., in ArcGIS-Rauset et al. 2012) or based upon an algorithm developed by Knopff et al. (2009); 3) visit a subset of clusters (we note that this field effort varies and is often poorly described-Merrill et al. 2010) to determine if the cluster is a predation event; 4) develop biologically relevant spatial and temporal covariates that describe each cluster; 5) apply a topranked model to all clusters for all marked animals, and apply a probability cutoff to classify clusters as either a predation or non-predation event; 6) divide the number of predation events by the sampling interval for each individual to estimate predation events made per unit time, also called kill rates.

Predicting predation events using GPS data to ultimately estimate kill rates and prey selection has been applied to a broad range of species, including African lions (Panthera leo-Tambling et al. 2010), bobcats (Lynx rufus-Svoboda et al. 2013), brown bears (Ursus arctos-Rauset et al. 2012), jaguars (Panthera onca-Cavalcanti and Gese 2010), leopards (Panthera pardus_-Pitman et al. 2012), Eurasian lynx (Lynx lynx-Mattisson et al. 2011), wolves (Canis lupus-Webb et al. 2008), tigers (Panthera tigris-Miller et al. 2010), and pumas (Knopff et al. 2009; Ruth et al. 2010; Smith et al. 2015). Until now, no test has evaluated the accuracy and precision of predicting predation events and prey selection from GPS clusters, which is of concern because this type of analysis has several major weaknesses.

The primary weakness of predation models is their inability to reliably differentiate between predation and resting events for clusters of short duration (Webb et al. 2008; Knopff et al. 2009; Blecha and Aldredge 2015). Should a model determine that short predation events are resting sites instead, model outputs underestimate kill rates, or in contrast, if models predict that some resting sites are predation events, outputs overestimate kill rates. To aid in model performance, researchers generally censor small prey from their analyses, and instead estimate kill rates only for medium and large prey (Knopff et al. 2009). The decision to exclude small prey is based on 2 assumptions: longer clusters are more likely predation than non-predation events; and longer clusters are indicative of larger prey (i.e., handling time and prey size are highly correlated). In reality, however, carnivore handling time (and the 
length of clusters) is influenced by prey size and other ecological pressures, such as competitors (e.g., Krofel et al. 2012). Researchers suggest model estimates are more accurate in systems in which carnivores kill 1 prey type of consistent size than in systems with multiple prey sizes, due to the influence of consistent versus irregular handling times on model performance (Knopff et al. 2009; Ruth et al. 2010). Many carnivores also suffer kleptoparasitism from dominant competitors (Scantlebury et al. 2014), sometimes reducing handling times of large kills to time parameters that overlap with resting sites (Ruth et al. 2010). For example, African lions and spotted hyenas (Crocuta crocuta) commandeer prey from wild dogs (Lycaon pictus) and cheetahs (Acinonyx jubatus) (Creel and Creel 1996; Scantlebury et al. 2014), and Eurasian lynx and pumas suffer kleptoparasitism by bears (Ursus spp.) (Krofel et al. 2012; Elbroch et al. 2015). Indirect effects driven by perceived risks (e.g., Elbroch and Wittmer 2013; Smith et al. 2015) also reduce carnivore handling time at large carcasses, which may also effect a model's ability to reliably identify predation events.

A 2nd weakness of predation models is in determining prey species for predation events identified by models, but not validated in the field. In fact, while there have been attempts to classify prey into categories based on size (Knopff et al. 2009; Miller et al. 2010; Ruth et al. 2010), the ability of predation models to accurately predict predation events by species remains generally poor (see Williams et al. 2014 for advances with accelerometer data that may improve future application). As a result, inaccurate predictions can bias species-specific kill rates of rare or threatened species (e.g., Johnson et al. 2013).

We used 2 methods to evaluate the reliability of predictive modeling in determining predation events and diet composition for 3 puma populations (Chilean Patagonia, Colorado, and California) with different prey assemblages and different effects on handling time at carcasses. First, we applied "selective" subsampling of our full data set to build multiple models to explore the accuracy of model predictions, as compared with predation events determined via field surveys of GPS clusters. Second, we employed "random" subsampling of our full data set to build multiple models to explore the precision of model outputs. We predicted that the removal of short clusters $(<12$ and $<24 \mathrm{~h})$ via selective subsampling would improve model performance because models would then more reliably differentiate between resting sites and predation events; however, we also predicted that models would underestimate the number of predation events (Ruth et al. 2010). As consistent handling time should increase model performance (Knopff et al. 2009), we hypothesized that the accuracy of predation estimates are inversely related to the complexity of prey assemblages. In particular, our hypothesis predicts that estimates would be most accurate for California, a single-ungulate prey system, followed by Colorado, a 2-ungulate system, and lastly, Patagonia, a 3-ungulate system. Finally, we also predicted that simulating reduced field efforts would underestimate the diversity of prey killed by pumas.

\section{Materials ANd Methods}

Study areas.-We conducted research in 3 study areas: Chilean Patagonia in 2008-2010, western Colorado in 20112013, and northern California in 2009-2013.

The Patagonia study area is located in the southern portion of Chile's Aysén District (W 47.800, S 72.000). The landscape is dominated by rugged mountains, and during the time of the study, the study area contained a mixture of 3 vegetation classes: $53 \%$ open Patagonia steppe in which pumas were vulnerable to harassment by condors (Elbroch and Wittmer 2013) and ranchers (Kissling et al. 2009) throughout the year; highelevation deciduous forests dominated by lenga (Nothofagus pumilio); and lower-elevation shrub communities. Pumas in our Patagonia study area were part of a diverse predator-prey system that included 2 native ungulate species, guanacos (Lama guanicoe) and huemul deer (Hippocamelus bisulcus) as well as introduced domestic sheep (Ovis aries) and European hares (Lepus europaeus). Persecution of pumas in the study area was intense until 2004 when a cessation on predator control was initiated over most of the study area (Wittmer et al. 2013).

The Colorado study area is located near the town of De Beque (W 39.385, S -108.324). The landscape is primarily valley bottoms supporting rangeland, highbush sagebrush (Artemisia spp.), and agriculture. During the time of the study, steep slopes were characterized by pinyon-juniper (Pinus edulis and Juniperus spp.) woodlands, Gambel oak (Quercus gambeli) forests, and rangeland shrub communities (Atriplex spp.). High-elevation plateaus included mixed conifer (Pseudotsuga mensiesii and Pinus contorta) and aspen (Populus tremuloides) forests, as well as rangeland shrubs. The study area supported 2 native ungulate species, elk (Cervus canadensis) and mule deer (Odocoileus hemionus), and large numbers of cattle (Bos primigenius). Pumas in Colorado suffered seasonal kleptoparasitism by American black bears (Ursus americanus) that typically displaced them from their kills (Elbroch et al. 2015). Hunters also pursued pumas seasonally with hounds and firearms during legal, managed hunting seasons.

Our California study area is located in the Mendocino National Forest near the town of Covelo (W 39.738, S -123.160 ). During the time of the study, vegetation communities varied from grasslands and mixed chaparral at low elevations, mixed coniferous forests dominated by pine (Pinus spp.) and Douglas fir (Pseudotsuga menziesii) at mid-elevations, and true fir (Abies spp.) forests at high elevations. Black-tailed deer (Odocoileus hemionus columbianus) were the only abundant ungulate prey in the area. Similar to Colorado, pumas suffered seasonal kleptoparasitism by black bears (Allen et al. 2015), but were not subject to legal hunting.

Puma captures and collar programming.-We predominantly relied on hounds to capture pumas in winter. Hounds forced pumas to retreat to a tree or rocky outcrop where we could safely immobilize them. We also used box traps in Colorado and California, and foot snares in Colorado to capture pumas during warmer months. We equipped traps with telemetry devices and monitored them at a minimum of twice per day ( $1 \mathrm{~h}$ after sunrise and again prior to midnight). In Patagonia and 
Colorado, we anesthetized pumas with ketamine (2.5-3.0 mg/ $\mathrm{kg}$ ) and medetomidine $(0.075 \mathrm{mg} / \mathrm{kg})$, and in California, we anesthetized pumas with $2.2 \mathrm{mg} / \mathrm{kg}$ of Telazol (tiletamine $\mathrm{HCl}$ and zolazepam HCl; Fort Dodge Animal Health, Fort Dodge, Iowa). Once a puma was immobilized, we recorded their standard morphological measurements, temperature, heart rate, and respiration at 5-min intervals. We also collected blood samples for genetic analyses, and fitted each animal with either an Argos or Iridium GPS collar (Lotek 7000SAW or Lotek IridiumTrack M; Lotek Wireless, Newmarket, Ontario, Canada). Once the animal was processed, we reversed the effects of medetomidine with atipamezole $(0.375 \mathrm{mg} / \mathrm{kg})$ and released pumas at capture sites. All capture and handling procedures adhered to guidelines developed by the American Society of Mammalogists (Sikes et al. 2016) and were approved by the Institutional Animal Care and Use Committee at the University of California, Davis (Protocols 13252, 15341, 16645, 16886).

We programmed GPS collars differently across study areas. In Patagonia and California, we programmed collars to acquire location data every $2 \mathrm{~h}$ and to upload location data to Argos satellites every 3 days. In Colorado, we programmed collars to acquire location data at 30-min, 1-h, or 2-h intervals, depending on collar type. Argos collars uploaded location data every 3 days, and Iridium collars uploaded data once or twice daily.

Cluster identification and field investigations.-We identified GPS clusters by plotting GPS locations in ArcGIS or Google Earth (Google Inc. 2013). We defined GPS clusters as any 2 or more locations (representing a time period of $\geq 2 \mathrm{~h}$ ) that occurred within 1 week of each other and within $150 \mathrm{~m}$ of each other. Further, clusters needed to contain a minimum of 1 GPS location recorded during crepuscular or nocturnal periods, which varied depending on season and study area (Elbroch et al. 2014). We transferred location data to handheld GPS units and systematically searched for prey remains within a 30-m radius circle centered on each GPS location in the cluster. CyberTracker certified all personnel conducting field investigations to ensure reliable and standardized prey identification (Evans et al. 2009). Personnel identified prey remains by their tissues (hair, skin, rumen, and bone fragments), assessed the state of prey remains (e.g., the lay of the carcass, which parts were fed upon), and determined the presence and location of bite marks to determine if the puma had killed or scavenged the prey. We classified all clusters as predation (1) and nonpredation (0) events (e.g., beds, scavenging events).

We attempted to visit every cluster for every puma in the field to verify the correct classification of a predation event by prey species. We recognize that our approach was almost certainly imperfect, even with the best of intentions, and that well-trained observers can miss prey remains during site investigations. Nevertheless, our intensive field surveys served as our validation method in that we compared our findings to those obtained via predictive modeling and simulations of reduced field effort.

Simulating reduced field effort.-Following established protocols in the literature, we excluded clusters from our full data set where pumas scavenged animals or killed prey weighing
$<5 \mathrm{~kg}$ (Knopff et al. 2009). The 5-kg cutoff used by Knopff et al. (2009) helped models distinguish between resting sites and kill sites, while also allowing the inclusion of mediumsized prey $(>5 \mathrm{~kg}$ ) species in model development, including American beaver (Castor canadensis) and North American porcupine (Erethizon dorsatum). We excluded clusters that we were unable to visit within a year of their initiation, due to collar malfunctions, seasonal road closures, or delayed access to private lands. We called this reduced data set our "full" data set.

Then, we simulated reduced field efforts by further subsampling our data sets in 2 ways. First, we created 2 subsets of our full data set by excluding clusters $<12$ and $<24 \mathrm{~h}$ in duration. Short clusters $(<24 \mathrm{~h})$ are often assumed to be non-predation events. For example, $24 \mathrm{~h}$ is a common cutoff employed by researchers deciding whether or not to visit a cluster in the field (e.g., Svoboda et al. 2013) or used in modeling as an indicator of predation and non-predation events (e.g., Ruth et al. 2010; Smith et al. 2015). Second, we subsampled our data randomly, omitting $5 \%, 15 \%, 25 \%$, and $50 \%$ of our clusters in each study area, to explore the effects of reduced field efforts on model precision.

Estimating puma predation with predictive modeling.We conducted separate analyses for each study area. Based on results from previous research, we included the following explanatory covariates: 1) the time in hours that a puma was associated with the cluster (Duration); 2) a binary term indicating whether or not the cluster duration was $>24 \mathrm{~h}$ (coded 1 or 0, respectively; Binary); 3) the average distance of each GPS location to the cluster centroid (Distance); 4) the percent of GPS points in a cluster that occurred between 1900 and $0600 \mathrm{~h}$ (PercentNight); and 5) the percent of GPS points that were located within the cluster radius over the cluster duration (Fidelity). For each analysis, we restricted the covariates to include only those correlated at $r<0.7$ (Webb et al. 2008; Miller et al. 2010).

We used generalized linear mixed models with a random intercept for individual pumas to account for the unbalanced sample among individuals, the autocorrelation of repeated samples within individuals, and individual differences in foraging behavior (Bolker et al. 2009; Lowrey et al. 2016). We used the R package lme4 to fit models to data with a logit link and a binomial error structure (Bates et al. 2013; R Core Team 2013). We generated sets of candidate model using all combinations of covariates and selected the best predictive model using Akaike Information Criterion (AIC-Burnham and Anderson 2002). When top models were within 2 AIC units, we selected the simplest model to avoid including uninformative parameters (Arnold 2010). We discretized fitted values into a binary response (predation versus non-predation) by selecting an optimum cutoff derived from sensitivity and specificity curves (Webb et al. 2008; Knopff et al. 2009). We evaluated the top-ranked models using receiver-operator characteristic (ROC) curves and adapted $k$-folds crossvalidation (Boyce et al. 2002) where each fold represented the clusters from individual 1 through $k$ (i.e., leave-one-out cross-validation). 
We repeated the same model building and selection procedures with our full data sets of clusters and each of our selective simulations of reduced field efforts (excluding clusters $<12$ and $<24 \mathrm{~h}$ ), thus allowing the model structure to vary as a function of reduced field effort. We then applied the top-ranked models from each analysis to our full data sets in order to estimate the total number of predation events in each study area. We generated $S E$ estimates using bootstrap techniques by resembling and discretizing the fitted values and summing the number of kills for each of 10,000 iterations.

For our random simulations of reduced field effort, we did not allow the model structure to vary for each iteration; instead, we fit the top model from the full data sets to all subsampled data sets. Following a simulation framework, we then generated 10,000 estimates of the number of predation events for each study area and randomly reduced data set (i.e., omitting 5\%, $15 \%, 25 \%$, and $50 \%$ of the full data set). Finally, we estimated the mean and $S D$ of predation events to examine how randomly excluding data influenced precision. We expected accuracy to be consistent across simulations because we maintained model structure across different random subsampling.

Puma diet composition.-We summarized puma diet, as well as estimated Shannon's diversity index $(H)$ and Evenness (Shannon 1948; Krebs 1999) scores for our complete data set and our subsampled data sets, to investigate the effect of less field effort on detecting the diversity of prey killed by pumas. $H$ is a species richness measure inclusive of the number of species in a sample and their relative abundances, whereas Evenness is a measure of how diversity is proportionally distributed. Both measures are critical to understanding diversity (Tuomisto 2012), and high values indicate greater prey diversity that is evenly distributed across prey types.

\section{Results}

Field efforts and total clusters.-We captured 26 pumas in 3 study areas but excluded 2 individuals because we only visited 3 of their clusters (Supplementary Data SD1). We visited a total of 1,896 clusters, but excluded 18 scavenging events and an additional 20 clusters that we did not investigate within 1 year. We removed an additional 100 clusters where we discovered prey $<5 \mathrm{~kg}$ to create a data set of 1,752 clusters from 24 pumas $($ California $=355$, Colorado $=1,036$, Patagonia $=361$; Table 1 ; Supplementary Data SD2). We visited $73 \pm 50$ clusters for each individual and investigated clusters within $38 \pm 70$ days of pumas leaving the site.

Comparisons between predation estimates.-Our estimates of the number of predation events for each study area varied among selective subsets. In all study areas, our estimates of predation determined from models using the full data set best approximated observed predation determined from intensive field monitoring, as compared to reduced field efforts that excluded clusters $<12$ and $<24 \mathrm{~h}$ in length (Fig. 1). As expected, these reduced models underestimated the number of predation events even though models performed well (Table 2). In California and Colorado, data sets excluding clusters $<12$
Table 1.-Clusters identified as predation (kills) versus non-predation events (non-kills) in California (CA), Colorado (CO), and Chilean Patagonia (Pat) as we selectively subsampled the data (those that exclude clusters $<12$ and $<24 \mathrm{~h}$ in duration).

\begin{tabular}{llrrr}
\hline Study area & Data used & Total & Kills & Non-kills \\
\hline CA & Full & 355 & 184 & 171 \\
CA & Excl. $<12 \mathrm{~h}$ & 191 & 164 & 24 \\
CA & Excl. $<24 \mathrm{~h}$ & 136 & 131 & 5 \\
CO & Full & 1,036 & 474 & 562 \\
CO & Excl. $<12 \mathrm{~h}$ & 547 & 416 & 131 \\
CO & Excl. $<24 \mathrm{~h}$ & 388 & 337 & 51 \\
Pat & Full & 361 & 215 & 146 \\
Pat & Excl. $<12 \mathrm{~h}$ & 187 & 156 & 31 \\
Pat & Excl. $<24 \mathrm{~h}$ & 136 & 122 & 14 \\
\hline
\end{tabular}

and $<24 \mathrm{~h}$ in length underestimated the number of predation events. In Patagonia, however, predation was both greatly underestimated for the data set excluding clusters $<12 \mathrm{~h}$ in length and greatly overestimated for the data set excluding clusters $<24$ h in length (Fig. 1).

Duration was the best predictor of clusters being predation events in all study areas (Supplementary Data SD3). The Binary term was highly correlated $(r>0.7)$ with Duration in all study areas and was removed from all candidate sets. Predation events were characterized by a negative relationship with Average Distance and a positive relationship with Fidelity, both indicating that pumas generally remained proximal to kill sites. PercentNight generally had a positive relationship with predation events, although these results were not consistent across study areas (Supplementary Data SD3). Models generally performed well when evaluated with ROC curves and leave-one-out cross-validation (Table 2). We note that within California and Colorado, there was a positive correlation between area under the ROC curve and the amount of data used to build models. The relationship between area under the ROC curve and the number of clusters was less clear in Patagonia (Table 2).

Selectively removing clusters $(<12$ and $<24 \mathrm{~h})$ resulted in a larger proportion of predation events versus resting sites (Table 1) because eliminating short clusters increased the cutoff used to predict the probability of a predation event (Table 2). As expected, removing short clusters improved model performance, especially those that excluded $<24$-h clusters (Table 2 ). We also found evidence supporting the prediction that California models would be more accurate than the other study areas due to the simplicity of the prey system; however, this was not the case for the other study areas, as the Patagonia results (3-ungulate system) were more accurate than those of Colorado, a 2-ungulate system.

Our results showed that random subsampling changed the precision rather than accuracy of parameter estimates, except in the $5 \%$ reduction of clusters in Colorado (Fig. 2). Precision, however, did not change consistently across study areas. In Colorado, the spread of predation estimates derived from reduced data sets was relatively constant, at least until $75 \%$ of clusters were removed from analyses. However, just a $25 \%$ 


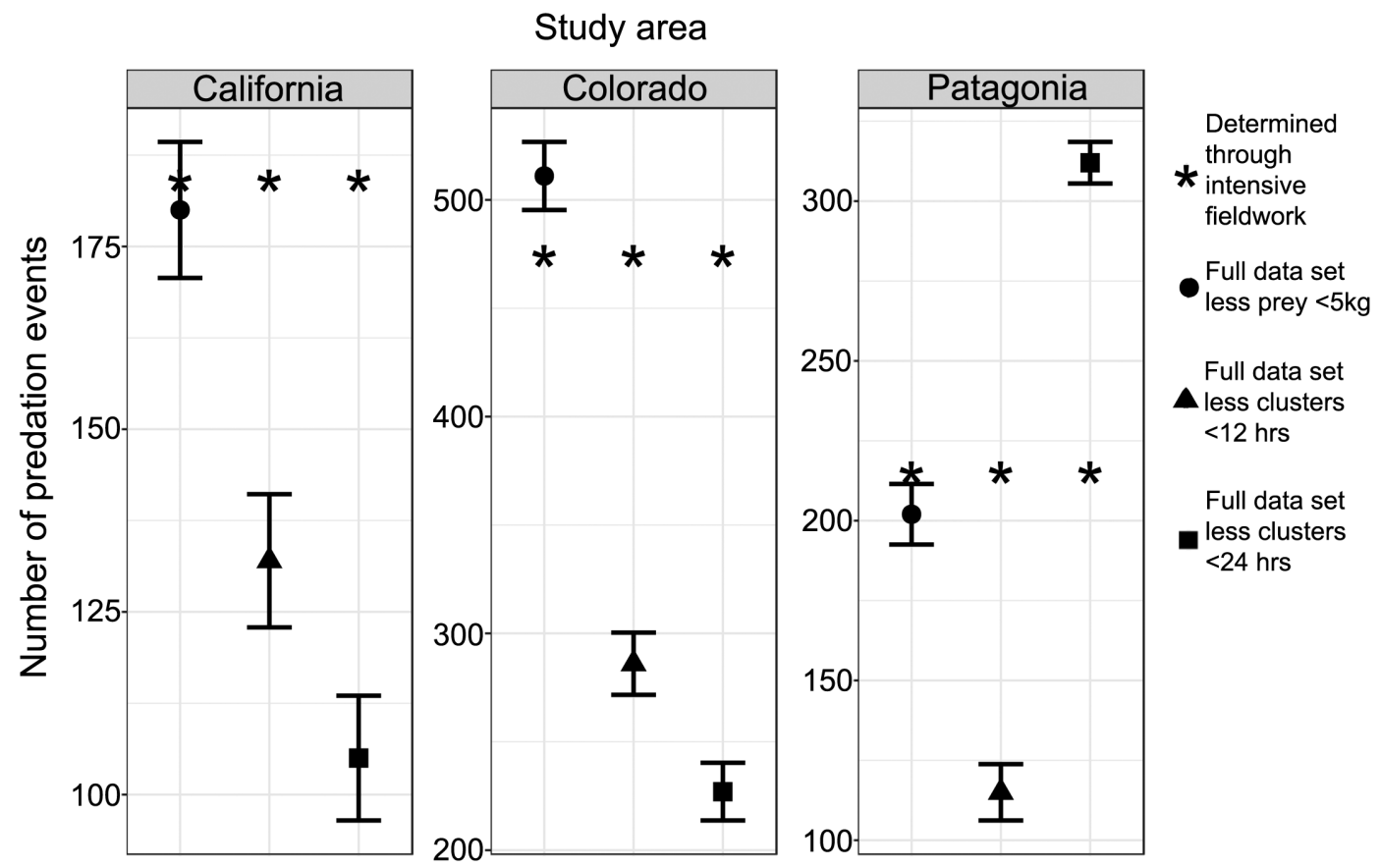

Fig. 1. - Mean number $( \pm 95 \%$ CIs) of prey killed by pumas (Puma concolor) in California, Colorado, and Patagonia, as estimated with predictive modeling with our full data set and 2 reduced data sets (excluding clusters $<12$ and $<24 \mathrm{~h}$ in duration). An asterisk $(*)$ denotes the number of prey determined from intensive fieldwork visiting GPS clusters.

Table 2.- - Top models used to estimate predation events for each data set (full; and those that exclude clusters $<12$ and $<24 \mathrm{~h}$ in duration) in California (CA), Colorado (CO), and Chilean Patagonia (Pat). Covariate coefficients are reported in Supplementary Data SD3. ROC $=$ receiveroperator characteristic.

\begin{tabular}{|c|c|c|c|c|c|c|}
\hline Study area & Effort & Variables & $\mathrm{K}$ & Cutoff & Area under ROC curve & Leave-one-out classification success \\
\hline CA & Full & Duration, Percent Night Points, (1IIndID) ${ }^{\mathrm{a}}$ & 4 & 0.458 & 0.960 & 0.868 \\
\hline $\mathrm{CA}$ & Excl. $<12 \mathrm{~h}$ & Duration, (1|IndID) & 3 & 0.498 & 0.899 & 0.864 \\
\hline $\mathrm{CA}$ & Excl. $<24 \mathrm{~h}$ & Duration, (1|IndID) & 3 & 0.801 & 0.915 & 0.919 \\
\hline $\mathrm{CO}$ & Full & Duration, (1IIndID) & 3 & 0.437 & 0.923 & 0.832 \\
\hline $\mathrm{CO}$ & Excl. $<12 \mathrm{~h}$ & Duration, Average Distance, (1IIndID) & 4 & 0.554 & 0.844 & 0.793 \\
\hline $\mathrm{CO}$ & Excl. $<24 \mathrm{~h}$ & Duration, Average Distance, Fidelity, (1IIndID) & 5 & 0.632 & 0.834 & 0.855 \\
\hline Pat & Full data & Duration, Percent Night Points, (1IIndID) & 4 & 0.475 & 0.876 & 0.701 \\
\hline Pat & Excl. $<12 \mathrm{~h}$ & Duration, Percent Night Points, (1IIndID) & 4 & 0.577 & 0.840 & 0.845 \\
\hline Pat & Excl. $<24 \mathrm{~h}$ & $\begin{array}{l}\text { Duration, Percent Night Points, Fidelity, } \\
\text { Average Distance, (1IIndID) }\end{array}$ & 6 & 0.785 & 0.942 & 0.852 \\
\hline
\end{tabular}

${ }^{a}$ Represents random intercept for each individual.

reduction in the number of clusters tripled the spread of potential predation estimates for California and doubled the spread of potential predation estimates for Patagonia.

Puma diet composition.-We documented 973 prey killed by pumas, but excluded 100 of these records $(9.7 \%)$ from our analyses because prey were $<5 \mathrm{~kg}$ (e.g., ground squirrels, Spermophilus spp.; ruffed grouse, Bonasa umbellus). After excluding small prey, puma diet consisted of $88 \%$ guanaco, $9 \%$ domestic sheep, and 3\% huemul in Patagonia; $80 \%$ mule deer and elk and 20\% medium-sized prey in Colorado; and 96\% black-tailed deer and $4 \%$ other prey in California.

Removing clusters $<12$ and $<24 \mathrm{~h}$ in length reduced the number, diversity $(H)$, and evenness of prey, and overestimated large-bodied prey in puma diets (Fig. 3; Supplementary Data SD4). California puma diets included the most small-bodied prey and were therefore most impacted by reduced field efforts: $H$ dropped by $45 \%$ when excluding clusters $<12 \mathrm{~h}$ and $57 \%$ when excluding clusters $<24 \mathrm{~h}$ long (Fig. 3 ). In contrast, the diets of Colorado pumas included the smallest proportion of small-bodied prey. $H$ dropped by $9 \%$ and $16 \%$ when excluding $<12$-h and $<24$-h clusters, respectively.

\section{DiscuSsion}

GPS collars have revolutionized wildlife research; however, it is imperative to understand their current limitations (Hebblewhite and Haydon 2010). Statistical models that use GPS location data to predict carnivore predation provide clear benefits over intensive fieldwork (e.g., less effort and cost). Our analyses, however, showed that reducing field efforts by excluding 


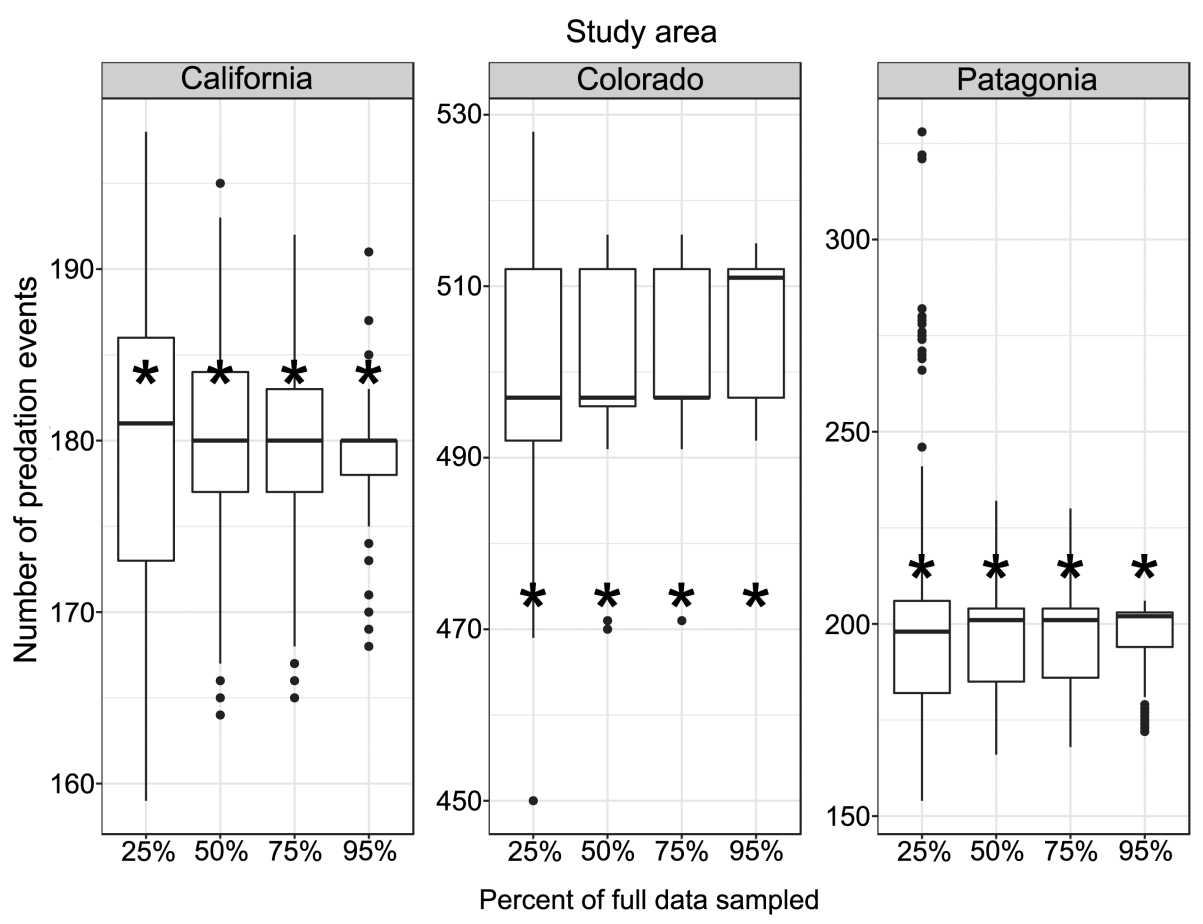

Fig. 2.-Box plots of predation estimates from top models, reflecting the precision of model outputs, as produced through 10,000 simulations. Simulations were repeated with different proportions of the original data for each study area to understand the effect of randomly reduced field efforts on detecting predation events. An asterisk $(*)$ indicates the number of kills determined through intensive field monitoring.

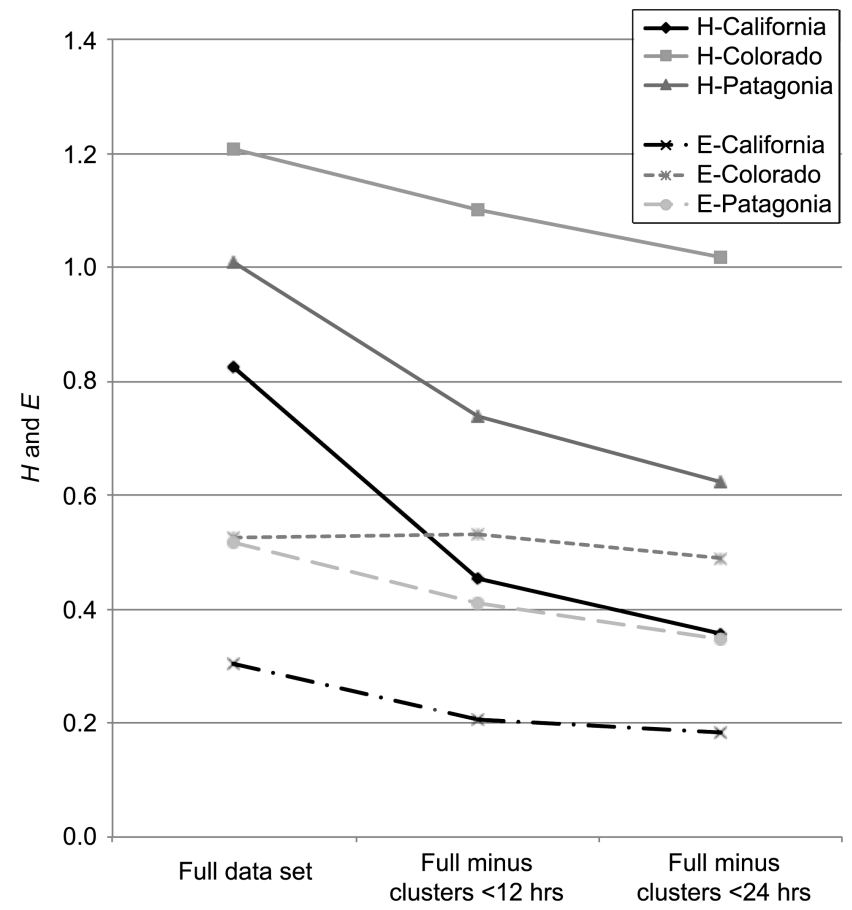

Fig. 3. - Changes in species richness $(H)$ and evenness $(E)$ in the diets of pumas (Puma concolor) in California, Colorado, and Patagonia for the full data set and 2 reduced data sets (those that exclude clusters $<$ 12 and $<24 \mathrm{~h}$ in duration).

clusters $<12$ or $<24 \mathrm{~h}$ in length paradoxically improved model performance yet unpredictably biased the identification of predation events, which were generally underestimated. Further, our results suggest that randomly subsampling GPS clusters for field verification to save project resources may yield kill rates with confidence intervals too wide to make meaningful inferences. As expected, we also showed that excluding field surveys of short clusters decreased our ability to accurately measure prey diversity. In short, our results underscored the importance of fieldwork in describing carnivore kill rates and diet composition, which are vital to understanding predator-prey dynamics and informing wildlife management.

When researchers remove clusters $<12$ or $<24 \mathrm{~h}$ in length from their data sets, input data (predation versus non-predation events) become skewed toward predation events (Table 1) rather than more equally representing resting and predation events. Such skew in the data forces models to estimate predation with limited information on the characterization of non-predation events, which likely biases results. Removing clusters may also exacerbate model confusion in systems where handling time varies due to different prey types, kleptoparasitism, or indirect perceived risks (Ruth et al. 2010), as models must then differentiate a small sample of resting sites from kill sites with overlapping time parameters. For example, in Patagonia, kills of sheep were consistently misclassified as non-predation events and suffered a Type II error rate (false negative) of $72 \%$. Patagonia sheep are a domestic species smaller than local ungulates and strongly associated with human activity; pumas appear to be aware of the inherent dangers of remaining near sheep they kill. Pumas handled sheep for shorter intervals (clusters averaged $9.11 \pm 10.12$ $[S D] \mathrm{h})$ when compared to native guanacos $(41.38 \pm 44.16 \mathrm{~h})$; therefore, models unexpectedly misclassified many sheep kills as non-predation events. The handling time associated with guanaco kills in Patagonia was also highly variable. Guanacos killed in open grasslands were quickly abandoned and usurped 
by Andean condors (Vultur gryphus), which resulted in short clusters for large prey as well (Elbroch and Wittmer 2013).

There is further evidence in the published literature for unexpected model outputs following the removal of short clusters. For example, Smith et al. (2015) visited a subset of GPS clusters, excluded small prey associated with shorter clusters, and built predictive models to estimate puma kill rates on deer across a gradient of human housing density. Based on results from their top model with a 24-h cutoff for cluster length, they concluded that female pumas that occupied habitats closest to human development exhibited $36 \%$ higher kill rates than their rural counterparts, and speculated that this increase was due to an indirect effect driven by fear of people that reduced handling times at deer carcasses (Smith et al. 2015). In a follow-up paper, Smith et al. (2016) reported on puma diet in the same study area, but instead of estimating kill rates, they described puma diets as determined from the clusters they visited during field surveys. In contrast to their earlier paper, they reported that pumas killed fewer deer in areas with greater housing densities, even though deer were still abundant in these areas of high human use (Smith et al. 2016).

It seems predation models perform poorly in systems where dominant competitors and potential predators (e.g., Krofel et al. 2012; Scantlebury et al. 2014; Elbroch et al. 2015), including humans (Smith et al. 2015), frequently reduce carnivore handling time by pushing them from their kills (Ruth et al. 2010; Smith et al. 2016). In Colorado and California, where pumas exhibited reduced handling time at some clusters due to seasonal kleptoparasitism by American black bears, models underestimated the number of predation events; kleptoparasitism at these sites was frequent; however, pumas on average still fed for 2 days before a bear pushed a puma from its kill (Elbroch et al. 2015). In contrast, in Patagonia, where pumas sometimes exhibited severely reduced handling times due to persistent, year-round indirect effects of perceived risk of humans and condors (Elbroch and Wittmer 2013), models overestimated the number of predation events when we removed clusters < $24 \mathrm{~h}$ in length.

A potential solution to the conundrum of differentiating resting sites from small or large kills with short handling times is to integrate accelerometer or activity data collected by modern GPS collars. Both metrics measure collar movement and can be used to discern feeding carnivores (moving their heads) from resting animals (limited head movement) (Fröhlich et al. 2012; Blecha and Aldredge 2015). The incorporation of activity data to improve predation estimates calculated through predation modeling appears promising, and perhaps necessary, as the inclusion of coarse activity data increased estimated kill rates by 10\% (Blecha and Alldredge 2015).

As expected, our subsampling based on cluster duration also reduced both estimates of species richness and evenness for prey killed by pumas. Research based upon GPS data has shown that large carnivores utilize surprising numbers of small prey and this variation can be captured by visiting short clusters in the field to more accurately represent the trophic position and interactions of top predators (Latham et al. 2013; Allen et al. 2015). This is important given known variability in preferences for different prey sizes among individual carnivores, as well as different age and sex classes (e.g., Wittmer et al. 2014; Lowrey et al. 2016; Elbroch et al. 2017). When researchers bias their field investigations to visitation of longer clusters, they may also miss depredation of neonate ungulates, a potentially important diet source during certain seasons.

Logistic and financial constraints are a reality for researchers, yet our research findings emphasize the importance of conducting field surveys whenever possible. Our research highlighted how greater time afield can yield stronger inferences: more accurate proportional dietary estimates and kill rates for modeling predator-prey dynamics; and more complete understanding of the indirect effects and other ecological processes at play. Moreover, capturing and handling carnivores is inherently risky (Sikes et al. 2016), and as such, researchers should strive to gather as much data as possible from every marked animal to minimize handling additional animals unnecessarily.

Until predation models improve their ability to accurately predict predation events, we make the following 4 recommendations to researchers studying carnivore kill rates and prey selection: 1) Sample intensively for discrete time periods to determine seasonal kill rates, rather than subsample clusters and rely upon predictive modeling to estimate predation parameters across years. We recommend researchers sample for a minimum of 60 days and base the length of a cluster on species-specific handling times (e.g., social species feed in shorter intervals than solitary species); longer sampling periods are encouraged, as they will likely lead to more accurate estimates, especially in systems with different prey types (Knopff et al. 2009). Further, sample clusters at all times of day and night, as research has shown that diurnal clusters yield prey as well (e.g., Allen et al. 2015). 2) Sample different individuals and seasons that might yield different kill rates. For example, pumas exhibit sex- and age-specific differences in prey selection (Elbroch et al. 2017) and seasonal ungulate migrations, ungulate birth pulses, and variation in prey vulnerability all influence carnivore prey selection and kill rates at different times of year (Knopff et al. 2010; Metz et al. 2012). 3) When you decide to employ predictive models, which are still useful in study systems in which visiting every cluster is implausible due to private property or inhospitable terrain, we encourage researchers to publish their raw data. Include the number of clusters investigated and not investigated in the field, and the number of predation and nonpredation events associated with said investigations, to allow readers to better assess the potential accuracy and precision of modeling estimates. 4) It is possible that carnivores kill prey but move on quickly, or alternatively, they remain in place but impartial GPS data are transferred via satellites, and therefore a cluster does not form. Consider sampling a random subset of single GPS locations in the field in addition to clusters, or even better, employ other methods such as snow tracking to sample random sections of trail, so that one can report a measure of detectability and associated error with cluster methods to identify prey remains. 
The results of our analyses suggest that we should approach predation modeling and their associated outputs with caution, especially when predation events are predicted from a subset of GPS clusters sampled in the field. Carnivore handling time, which impacts predation model performance, varies with kleptoparasitism, indirect effects of fear, prey size, and other local ecology. Field surveys are necessary to account for this variation. The spatiotemporal characteristics of GPS clusters, however, can be used to identify the clusters researchers need to visit in the field (Knopff et al. 2009). Perhaps for now, this is the best application of cluster modeling.

\section{ACKNOWLEDGMENTS}

Funding for this work was generously provided by the National Science Foundation, the High Lonesome Ranch, National Geographic Society, Felidae Conservation Fund, Conservación Patagonica, the Robert and Patricia Switzer Foundation, Oregon Zoo Future for Wildlife Program, California Department of Fish and Wildlife, University of California, Davis, Victoria University of Wellington, the Hemispheric Institute on the Americas, American Society of Mammalogists, Charles and Elizabeth Gorst, F. Vanderbeck, N. Birtwell, and C. Bell. We thank the High Lonesome Ranch and Conservación Patagonica for inkind logistical support, and M. Allen, N. Wight, C. McFarland, J. Golla, B. Evans, and M. Nelson for fieldwork. We also thank C. Wilmers for stimulating discussions about GPS clusters and feedback on an earlier version of the manuscript.

\section{Supplementary Data}

Supplementary data are available at Journal of Mammalogy online.

Supplementary Data SD1.--Individual pumas (Puma concolor) monitored in our 3 study areas (California, Colorado, and Patagonia), and the number of clusters we visited for each puma, the number of kills we identified, and days we monitored each puma.

Supplementary Data SD2.-Clusters visited in the field, prey species, prey weight, and corresponding attributes used in predictive modeling.

Supplementary Data SD3.-Covariate coefficients in top models used in estimating predation events.

Supplementary Data SD4.-Diet composition of pumas (Puma concolor) in California, Colorado, and Patagonia based on intensive fieldwork and our simulated reduced data sets (excluding clusters $<12$ and $<24 \mathrm{~h}$ ).

\section{Literature Cited}

Ackerman, B. B., F. G. Lindzey, and T. P. Hemker. 1984. Cougar food habits in southern Utah. Journal of Wildlife Management 48:147-155

Allen, M. L., L. M. Elbroch, D. S. Casady, and H. U. Wittmer. 2015. The feeding and spatial ecology of mountain lions in the Mendocino National Forest, California. California Fish and Game 101:51-65.
Anderson, C. R., And F. G. Lindzey. 2003. Estimating cougar kill rates from GPS location clusters. Journal of Wildlife Management 67:307-316.

ARnold, T. W. 2010. Uninformative parameters and model selection using Akaike's Information Criterion. Journal of Wildlife Management 74:1175-1178.

Bates, D., M. Maechler, B. Bolker, and S. Walker. 2013. R code: lme4: linear mixed-effects models using Eigen and S4. R package version 1.0-5. http://CRAN.R-project.org/package=lme4. Accessed 1 July 2015.

Blecha, K. A., AND M. W. Alldredge. 2015. Improvements on GPS location cluster analysis for the prediction of large carnivore feeding activities: ground-truth detection probability and inclusion of activity sensor measures. PLoS One 10:e0138915.

BolKer, B. M., ET AL. 2009. Generalized linear mixed models: a practical guide for ecology and evolution. Trends in Ecology \& Evolution 24:127-135.

Boyce, M. S., R. V. Pierre, S. E. Nielsen, and F. K. A. Schmiegelow. 2002. Evaluating resource selection functions. Ecological Modeling 2:281-300.

Burnham, K. P., And D. R. Anderson. 2002. Model selection and multi-model inference: a practical information-theoretic approach. Springer, New York.

Cavalcanti, S. M. C., and E. M. Gese. 2010. Kill rates and predation patterns of jaguars (Panthera onca) in the southern Pantanal, Brazil. Journal of Mammalogy 91:722-736.

Creel, S., and N. M. Creel. 1996. Limitation of African wild dogs by competition with larger carnivores. Conservation Biology 10:526-538.

Elbroch, L. M., M. L. Allen, B. H. Lowery, and H. U. Wittmer. 2014. The difference between killing and eating: ecological shortcomings of puma energetic models. Ecosphere 5:4.

Elbroch, L. M., J. Feltner, And H. Quigley. 2017. Stagedependent puma predation on dangerous prey. Journal of Zoology 302:164-170.

Elbroch, L. M., P. Lendrum, M. L. Allen, and H. U. Wittmer. 2015. No where to hide: pumas, black bears, and competition refuges. Behavioral Ecology 26:247-254.

Elbroch, L. M., and H. U. Wittmer. 2013. Nuisance ecology: do scavenging condors exact foraging costs on pumas in Patagonia? PLoS One 8:e53595.

Evans, J., C. Wharton, J. Packard, G. Caulkins, and M. Elbroch. 2009. Determining observer reliability in counts of river otter tracks. Journal of Wildlife Management 73:426-432.

Fröhlich, M., A. Berger, S. Kramer-Schadt, I. Heckmann, and Q. Martins. 2012. Complementing GPS cluster analysis with activity data for studies of leopard (Panthera pardus) diet. South African Journal of Wildlife Research 42:104-110.

Google Earth. 2013. Software available at https://www.google.com/ earth/.

Hebblewhite, M., and D. T. Haydon. 2010. Distinguishing technology from biology: a critical review of the use of GPS telemetry data in ecology. Philosophical Transactions of the Royal Society of London B 365:2303-2312.

Holling, C. S. 1959. Some characteristics of simple types of predation and parasitism. Canadian Entomologist 91:385-398.

Holt, R. D., AND J. H. LaWton. 1994. The ecological consequences of shared natural enemies. Annual Review in Ecology and Systematics 25:495-520.

Hopcraft, J. G. C., O. OlfF, and A. R. E. Sinclair. 2010. Herbivore, resources and risks: alternating regulation along primary 
environmental gradients in savannas. Trends in Ecology and Evolution 25:119-128.

Johnson, H. E., M. Hebblewhite, T. R. Stephenson, D. W. German, B. M. PIERCE, AND V. C. BleICH. 2013. Evaluating apparent competition in limiting the recovery of an endangered ungulate. Oecologia 171:295-307.

Kissling, W. D., N. Fernandez, and J. M. Paruelo. 2009. Spatial risk assessment of livestock exposure to pumas in Patagonia, Argentina. Ecography 32:807-817.

Knopff, K. H., A. A. Knopff, A. Kortello, and M. S. Boyce. 2010. Cougar kill-rate and prey composition in a multi-prey system. Journal of Wildlife Management 74:1435-1447.

Knopff, K. H., A. A. Knopff, M. B. Warren, and M. S. Boyce. 2009. Evaluating global positioning system telemetry techniques for estimating cougar predation parameters. Journal of Wildlife Management 73:586-597.

Krebs, C. J. 1999. Ecological methodology. Addison Wesley Longman, Boston, Massachusetts.

Krofel, M., I. Kos, and K. Jerina. 2012. The noble cats and the big bad scavengers: effects of dominant scavengers on solitary predators. Behavioral Ecology and Sociobiology 66:1297-1304.

Latham, A. D., M. C. Latham, K. H. KnopfF, M. Hebblewhite, and S. Boutin. 2013. Wolves, white-tailed deer, and beaver: implications of seasonal prey switching for woodland caribou declines. Ecography 36:1276-1290.

Lowrey, B., L. M. Elbroch, and L. Broberg. 2016. Is individual prey selection driven by chance or choice? A case study in cougars (Puma concolor). Mammal Research 61:353-359.

Mattisson, J., J. Odden, E. B. Nilsen, J. D. C. Linnell, J. Persson, AND H. ANDRÉN. 2011. Factors affecting Eurasian lynx kill rates on semi-domestic reindeer in northern Scandinavia: can ecological research contribute to the development of a fair compensation system? Biological Conservation 144:3009-3017.

MerriLl, E., ET AL. 2010. Building a mechanistic understanding of predation with GPS-based movement data. Philosophical Transactions of the Royal Society B 365:2279-2288.

Metz, M. C., D. W. Smith, J. A. Vucetich, D. R. Stahler, and R. O. PEterson. 2012. Seasonal patterns of predation for gray wolves in the multi-prey system of Yellowstone National Park. The Journal of Animal Ecology 81:553-563.

Miller, C. S., M. Hebblewhite, J. M. Goodrich, and D. G. Miquelle. 2010. Review of research methodologies for tigers: telemetry. Integrative Zoology 5:378-389.

Pitman, R. T., L. H. Swanepoel, and P. M. Ramsay. 2012. Predictive modeling of leopard predation using contextual global positioning system cluster analysis. Journal of Zoology 288:222-230.

R Core Team. 2013. R: A language and environment for statistical computing. R Foundation for Statistical Computing, Vienna, Austria. http://www.R-project.org/.

Rauset, G. R., J. Kindberg, and J. E. Swenson. 2012. Modeling female brown bear kill rates on moose calves using global positioning satellite data. Journal of Wildlife Management 76:1597-1606.
Ruth, T. K., P. C. Buotte, and H. B. Quigley. 2010. Comparing ground telemetry and global positioning system methods to determine cougar kill rates. Journal of Wildlife Management 74:1122-1133.

Scantlebury, D. M., ET AL. 2014. Flexible energetics of cheetah hunting strategies provide resistance against kleptoparasitism. Science 346:79-81.

Shannon, C. E. 1948. A mathematical theory of communication. Bell System Technical Journal 27:379-423.

Sikes, R. S., and The Animal Care and Use Committee of the American Society of Mammalogists. 2016. 2016 Guidelines of the American Society of Mammalogists for the use of wild mammals in research and education. Journal of Mammalogy 97:663-688.

Smith, J. A., Y. Wang, and C. C. Wilmers. 2015. Top carnivores increase their kill rates on prey as a response to human-induced fear. Proceedings of the Royal Society B 282:20142711.

Smith, J. A., Y. WANG, AND C. C. Wilmers. 2016. Spatial characteristics of residential development shift large carnivore prey habits. Journal of Wildlife Management 80:1040-1048.

Svoboda, N. J., J. L., Belant, D. E. Beyer, J. F. Duquette, and J. A. MARTIN. 2013. Identifying bobcat kill sites using a global positioning system. Wildlife Biology 19:78-86.

Tambling, C. J., E. Z. Cameron, J. T. Du Toit, and W. M. Getz. 2010. Methods for locating African lion kills using global positioning system movement data. Journal of Wildlife Management 74:549-556.

Tuomisto, H. 2012. An updated consumer's guide to evenness and related indices. Oikos 121:1203-1218.

Webb, N. F., M. Hebblewhite, and E. H. Merrill. 2008. Statistical methods for identifying wolf kill sites using global positioning system locations. Journal of Wildlife Management 72:798-807.

White, G. C., AND B. C. LuBow. 2002. Fitting population models to multiple sources of observed data. Journal of Wildlife Management 66:300-309.

WiLLIAMS, T. M., ET AL. 2014. Instantaneous energetics of puma kills reveal advantage of felid sneak attacks. Science 81:81-85.

Wittmer, H. U., L. M. Elbroch, and A. Marshall. 2013. Good intentions gone wrong: did conservation management threaten endangered huemul deer in the future Patagonia National Park? Oryx 47:393-402.

Wittmer, H. U., M. Hasenbank, M. Elbroch, and A. J. Marshall. 2014. Incorporating preferential prey selection and stochastic predation into population viability analysis for rare prey species. Biological Conservation 172:8-14.

Wittmer, H. U., R. Serrouya, L. M. Elbroch, and A. J. Marshall. 2013. Conservation strategies for species affected by apparent competition. Conservation Biology 27:254-260.

Submitted 27 June 2017. Accepted 1 December 2017.

Associate Editor was John Hopkins. 